\title{
Purpuric lip lesions in a young boy with IgA vasculitis
}

\author{
Aman Gupta ${ }^{1}$ (D) Megha Garg ${ }^{2}$
}

Received: 2 September 2020 / Revised: 24 October 2020 / Accepted: 27 October 2020 / Published online: 5 November 2020

(C) International League of Associations for Rheumatology (ILAR) 2020

\section{Presentation}

A previously healthy 6-year-old boy presented to the pediatrics department with skin rash, pain in the right ankle joint, and abdominal pain. Examination showed an afebrile child with diffuse palpable purpura over lower limbs (Fig. 1a), buttocks, trunk, upper limbs, palms, and soles with swelling and restricted movements of right ankle joint. Purpuric non-blanchable lesions were also noted over the lips (Fig. 1b). No pallor or lymphadenopathy was noted. Systemic and oral examination was unremarkable. Investigations showed normal hemoglobin (13.5 g/ $\mathrm{dL})$, platelet count $\left(402 \times 10^{9} / \mathrm{L}\right)$, urine examination and renal functions (Urea: $7.5 \mathrm{mg} / \mathrm{dl}$, creatinine $0.43 \mathrm{mg} / \mathrm{dl}$ ). Antinuclear antibody (ANA) by indirect immunofluorescence was negative. Skin biopsy was not performed. A diagnosis of IgA vasculitis was proffered. He received intravenous dexamethasone for painful abdomen followed by oral prednisolone for 7 days which was gradually tapered over 2 weeks. Purpuric lesions over lips resolved parallel with the generalized palpable purpura during follow-up visit after 2 weeks.

Aman Gupta

drgupta_aman@yahoo.com

1 Department of Pediatric Rheumatology and Immunology, MEDENS Hospital, Panchkula, Haryana 134113, India

2 Department of Dermatology \& Cosmetology, MEDENS Hospital, Panchkula, Haryana 134113, India

\section{Discussion}

IgA vasculitis (Henoch-Schonlein Purpura) is a small vessel vasculitis and one of the most common vasculitides of childhood [1]. Cutaneous manifestations in IgA vasculitis include palpable purpuric rashes predominantly involving the lower extremities and buttocks, but have also been described over other areas [2]. Lesions may vary from petechiae, ecchymoses to hemorrhagic bullae resulting in necrosis of the skin [3]. Mucosal lesions may include swelling, hyperaemia, petechiae, purpuric lesions, erosions, ulcers and hemorrhages involving the esophagus, stomach and intestines $[4,5]$. However, mucosal involvement with purpura over lips has rarely been reported in children with IgA vasculitis. These lesions should be differentiated from idiopathic thrombocytopenic purpura (unlikely in view of normal platelet count), systemic lupus erythematosus and other vasculitis syndromes (unlikely in view of negative ANA with typical clinical manifestations of IgA vasculitis) [1]. Skin lesions of IgA vasculitis may resemble cutaneous manifestations associated with certain periodic fever syndromes, including familial Mediterranean fever and periodic fever with aphthous stomatitis, pharyngitis and adenitis (PFAPA) syndrome [6, 7]. Further reports may be needed to elucidate the correlation between purpuric lesions at unusual sites with disease severity and renal involvement. 
Fig. 1 a Non-tender, non-pruritic purpuric lesions over bilateral lower extremities, and (b) Purpuric lesions involving inner surface of both lips in a young boy with IgA Vasculitis

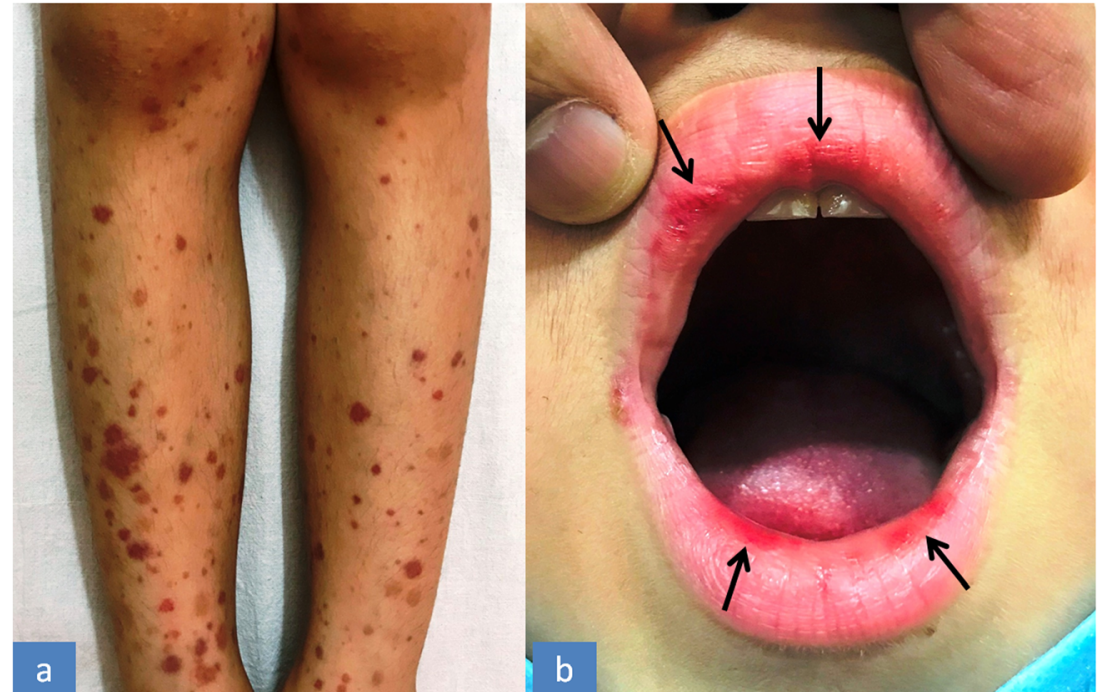

Data availability Not applicable.

\section{Compliance with ethical standards}

\section{Conflict of interest None.}

Code availability Not applicable.

Consent for publication Written informed consent was obtained from the parents for publication of this case report and related clinical images.

\section{References}

1. Brogan P, Bagga A (2015) Leukocytoclastic Vasculitis: HenochSchonlein Purpura and hypersensitivity Vasculitis. In: Petty RE, Laxer RM, Lindsley CB, Wedderburn LR (eds) Textbook of pediatric rheumatology, 7th edn. Elsevier Saunders, Philadelphia, pp 452 461
2. Mukherjee D, Majumdar I, Pal P, Dhar S, Kundu R (2017) Bullous Henoch-Schonlein purpura with involvement of face. Indian $\mathrm{J}$ Pediatr Dermatol 18:338-340

3. Nothhaft M, Klepper J, Kneitz H, Meyer T, Hamm H, Morbach H (2019) Hemorrhagic bullous Henoch-Schonlein Purpura: case report and review of the literature. Front Pediatr 6:413

4. Dara N, Dehghani SM, Haghighat M, Imanieh MH (2011) Tongue and esophageal involvement in Henoch-Schonlein purpura: a case report. J Pediatr Sci 3:e89

5. Dixit N, Raj C, Behera D, Panda M (2019) Drug-induced HenochSchonlein Purpura with severe gastrointestinal involvement. Indian J Drugs Dermatol 5:46-48

6. Barron KS, Kastner DL (2015) Periodic fever syndromes and other inherited autoinflammatory diseases. In: Petty RE, Laxer RM, Lindsley CB, Wedderburn LR (eds) Textbook of pediatric rheumatology, 7th edn. Elsevier Saunders, Philadelphia, pp 609-626

7. Lee WI, Yang MH, Lee KF, Chen LC, Lin SJ, Yeh KW, Huang JL (1999) PFAPA syndrome (periodic fever, Aphthous stomatitis, pharyngitis adenitis). Clin Rheumatol 18:207-213

Publisher's note Springer Nature remains neutral with regard to jurisdictional claims in published maps and institutional affiliations. 